\section{Summary}

The risk of fatal infections of B virus occurring in man as a result of the handling of monkeys or monkey tissue is very slight. It is important, however, in laboratories where monkeys are used to take precautions to protect the personnel from this infection. The precautions taken in our laboratory have been outlined and may be useful for those who are not familiar with the handling of monkeys.

We wish to thank the following for their advice in writing this account: Dr. A. J. Beale (Glaxo Laboratories), Dr. C. R. Coid (Royal College of Surgeons), Professor D. G. Evans (London School of Hygiene and Tropical Medicine), Mr. Oliver Graham-Jones
(Zoological Society of London), Dr. L. Goodwin (Nuffield Institute of Comparative Medicine), Mr. S. A. Keeble (Glaxo Laboratories), Dr. J. A. McFadzean (May and Baker Ltd.), Dr. Max McCowen (Eli Lilly Ltd), Dr. J. R. Napier (Royal Free Hospital), Mr. G. T. Tribe (Wellcome Research Laboratories), Dr. P. Stones (Pfizer Ltd.).

We especially wish to thank Mr. Keeble for the photograph of a B virus lesion and Mr. Oliver Graham-Jones for his advice on the sedation and recapture of an escaped monkey.

\section{REFERENCES}

Breen, G. E., Lamb, S. G., and Otaki, A. T. (1958). Brit. med. 7., 2, 22.

Hartley, E. G. (1964a). Vet. Rec., 76, 555

Hartley, E. G. (1964a). Vet. Rec., 76, 555

\title{
Erythrocyte Sedimentation Rate in Elderly Hospital In-patients
}

\author{
R. V. BOYD,* M.B., M.R.C.P., M.R.C.P.ED. ; B. I. HOFFBRAND, $\dagger$ M.A., B.M., M.R.C.P.
}

It has been firmly established that the erythrocyte sedimentation rate (E.S.R.) in apparently healthy elderly subjects is higher than the usually accepted normal limits (Olbrich, 1948; Wilhelm and Tillisch, 1951 ; Renbourn, 1952 ; Vignon, 1958 ; Hilder and Gunz, 1964). This fact is not widely appreciated, however, in spite of the increasingly high proportion of elderly patients seen in clinical practice, and receives scant attention in standard textbooks of haematology. The cause of the " raised" E.S.R. is unknown and has been attributed to occult infections, especially urinary (Vignon, 1958 ; van Zonneveld, 1961 ), and to changes in the plasma proteins (Olbrich, 1948).

The present study was undertaken to determine the significance in the elderly of what would generally be accepted as an abnormally raised E.S.R.- that is, one above $20 \mathrm{~mm}$. in the first hour (Ansell and Bywaters, 1958). Our aims were twofold : (1) to see what contribution, if any, occult infections of the urinary tract make to the E.S.R. in the elderly, and (2) to determine the upper limit of normal of the E.S.R. performed as a routine laboratory test in elderly hospital in-patients.

\section{Methods}

The patients studied were those admitted to the geriatric wards of University College Hospital between January 1963 and March 1964. In addition to the routine history, physical examination, and pathological investigations indicated, all patients had the following tests: haemoglobin estimation; white-cell count and differential ; E.S.R. by a modification of the Westergren (1926) method, blood being drawn up to the $100 \mathrm{~mm}$. mark ; mid-stream specimen of urine with prior penile and vulval cleansing; chest $x$-ray examination. In randomly selected patients the Hyland latex fixation test for rheumatoid factor was performed.

The hospital notes of these patients were examined after discharge. A small number of patients were immediately excluded from further study: those under 65 years of age, those with inadequate history or physical examination recorded, those who did not have one or more of the investigations listed above, and those who were observed in the ward for less than 48 hours.

\footnotetext{
* Consultant Physician in Geriatrics, Greenwich District Hospital ; late Geriatric Registrar, University College Hospital, London.
} † Medical Registrar, University College Hospital, London.
We next excluded those patients with a known cause for an abnormal E.S.R. The diagnoses were usually the obvious ones, such as infections (excluding occult infections' of the urinary tract, see below), malignancy, recent visceral infarctions and venous thrombosis, cardiac failure, and rheumatoid arthritis. We rigorously excluded, as possible cases of chronic bronchitis, all patients with a history of chronic or recurrent cough and sputum, all who were seen to be coughing or producing sputum, and all with added sounds on auscultation of the lungs. Patients with a haemoglobin of less than $12.6 \mathrm{~g} . / 100 \mathrm{ml}$. or with pulmonary $x$-ray changes were also not included for further study.

There were 303 patients aged 65 and over who had full clinical and pathological investigations and who were observed in the ward for 48 hours or more.

Control groups of male and female patients under the age of 60 admitted to the general medical and neurological wards were studied. These patients had all the investigations listed above, and, judged by the same criteria, had no cause for an abnormal E.S.R.

Criteria of Infection of the Urinary Tract.-Any pyuria consisting of 6 or more cells per $1 / 6$ high-power field with or without growth, or any mid-stream specimen of urine yielding a pure growth without pyuria, was regarded as indicating an infection of the urinary tract.

\section{Results}

Of the 303 patients 38 ( 6 male, 32 female) had no apparent . cause for an abnormal E.S.R., and a further 33 (4 male, 29 female) no apparent cause apart from an occult infection of the urinary tract (in only 4 of these latter 33 patients was there a sterile pyuria, positive cultures being obtained in the remainder). The Table compares the findings in these two groups. This shows no significant difference either in the mean E.S.R. or in the numbers with a conventionally raised E.S.R. Thus occult infections of the urinary tract do not appear to make any significant contribution to the E.S.R. in the vast majority of elderly hospital in-patients.

Considering these two groups together, Fig. 1 shows that in the age group 65 and over there is no tendency for the high 
E.S.R.s to occur in the older subjects. The mean of the 21 patients with an E.S.R. over 20 was 78.1 years, and that of the other 5081.5 years.

The control groups consisted of 31 males (mean age 42.6 years, range 12-59) and 32 females (mean age 43.3 years, range 16-58). The number of males in the geriatric group is too small to consider separately, and, in any case, previous studies have shown that there is no sex difference in E.S.R. values in the elderly (Olbrich, 1948 ; Renbourn, 1952). Fig. 2 compares

\begin{tabular}{c|c|c|c|c|c}
\multicolumn{8}{c}{ Comparison of Findings } \\
\hline & $\begin{array}{c}\text { No. of } \\
\text { Patients }\end{array}$ & $\begin{array}{c}\text { Mean } \\
\text { Age } \\
\text { (years) }\end{array}$ & $\begin{array}{c}\text { E.S.R. } \\
(\mathrm{mm} . / \mathrm{hr} .)\end{array}$ & $\begin{array}{c}\text { No. with } \\
\text { E.S.R. } \\
>20\end{array}$ \\
\hline $\begin{array}{c}\text { No apparent cause for abnor- } \\
\text { mal E.S.R. }\end{array}$ & 38 & 77.2 & 16.3 & $2-42$ & $11(29 \%)$ \\
$\begin{array}{c}\text { No apparent cause for abnor- } \\
\text { mal E.S.R. except for } \\
\text { occult infection of urinary } \\
\text { tract } \ldots\end{array}$ & 33 & 81.5 & 16.0 & $6-32$ & $10(33 \%)$
\end{tabular}

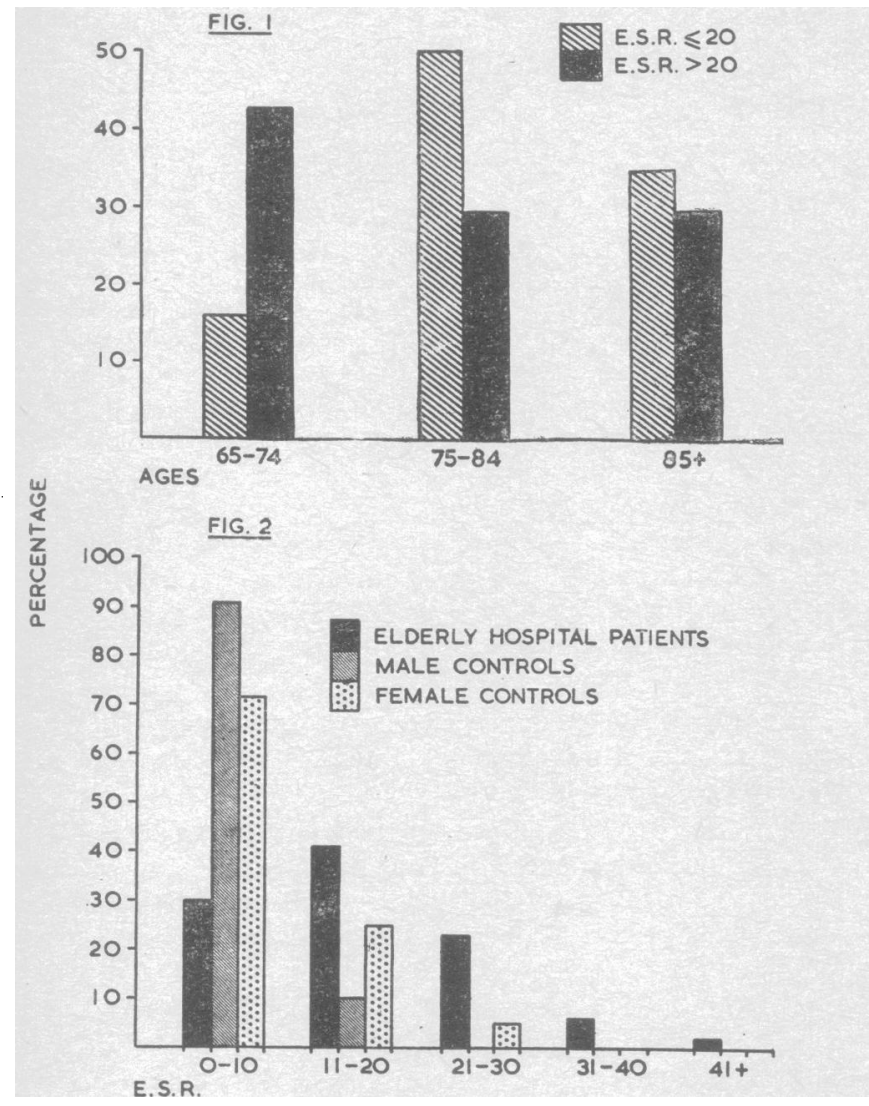

FIg. 1.-Distribution of ages of 71 elderly patients (50 with

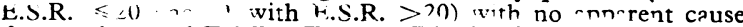
for an abnormal E.S.R. FIG. 2.-Distribution of E.S.R. values in 71 elderiy pacents and 63 younjer cos.rols (ol male, 32 female) with no apparent cause for an abnormal E.S.R.

the incidence of E.S.R. values in the geriatric and control groups. This shows the higher values in the geriatric patients, together with the well-recognized difference between the values of the male and female controls. An E.S.R. over 20 was found in $21(29.5 \%)$ of the geriatric patients compared with $2(3.2 \%)$ of the control group-a highly significant difference $(P=0.00014$ by the Chi-squared test).

Latex Tests.-These were performed in 35 of the 50 geriatric patients with an E.S.R. of $2 \theta$ and under with 6 positive results $(17.2 \%)$, and in 14 of those with an E.S.R. over 20 with 2 positive results $(14.3 \%)$.

Follow-up.-As in all departments of geriatrics, there is a high readmission rate. The notes of the 71 geriatric patients with no cause for an abnormal E.S.R. (ignoring occult infections of the urinary tract) were re-examined nine months after the last patient was included in the investigation. Information was available on 23 of the 50 patients with an E.S.R. of 20 and under and on 13 of the 21 with an E.S.R. of over 20 . Of these patients $8(34.8 \%)$ of the former had died and $3(23.0 \%)$ of the latter. Such a follow-up is of course incomplete, but the conventionally raised E.S.R. does not appear, from these figures, to signify a graver prognosis.

\section{Discussion}

We have found E.S.R. levels as high as $40 \mathrm{~mm} . / \mathrm{hr}$. in elderly subjects, without any apparent cause. This observation agrees with the results of Wilhelm and Tillisch's (1951) work based on a large retrospective study of case-notes. These authors give an upper limit of normal for the E.S.R. in the elderly of $35-40 \mathrm{~mm}$. $/ \mathrm{hr}$.

Many physicians are aware of the not infrequent occurrence of a conventionally raised E.S.R. without obvious cause in elderly patients. It is still probable, however, that many investigations are done unnecessarily on the basis of such a finding.

Though it has been suggested that occult infections of the urinary tract are responsible for the higher E.S.R.s found in the elderly (Vignon, 1958), no previous attempt appears to have been made to elucidate this point. Occult infections of the urinary tract occurred in $104(34.3 \%)$ of our total of 303 patients over the age of 65 , compared with $2(3.2 \%)$ of the 63 controls. The lack of any effect of these infections on the E.S.R. suggests that there is little tissue damage, and this is consistent with the absence of symptoms.

Olbrich (1948) produced evidence to show that the higher E.S.R. of the elderly is related to changes in the plasma proteins. Such changes could also account for the higher incidence of positive rheumatoid latex fixation tests in the elderly (Ball and Lawrence, 1961). We have not found, however, any correlation between positive latex tests and a conventionally raised E.S.R. in patients over the age of 65 .

\section{Summary}

The conventionally accepted upper limit of normal of the E.S.R. is not applicable to a hospital in-patient population aged over 65 years. The probable upper limit of normal for this group is about $40 \mathrm{~mm}$./hr. Nearly one-third of elderly patients without any apparent cause for an abnormal E.S.R. had values over $20 \mathrm{~mm}$. $/ \mathrm{hr}$., an incidence significantly different from that of younger control groups.

Occult infections of the urinary tract are very common in the elderly, and were found in $34.3 \%$ of all in-patients over 65 during the period studied. These infections do not contribute to the higher E.S.R. levels in the elderly.

Rheumatoid latex fixation tests are more often positive in older age groups, but no correlation was found between conventionally raised E.S.R.s and positive latex tests in the patients studied.

We are indebted to Lord Amulree for much encouragement during this study, and to the late Dr. David Riley for his help with the laboratory investigations.

\section{REFERENCES}

Ansell, B., and Bywaters, E. G. L. (1958). Brit. med. F., 1, 3\%2. Ball, J., and Lawrence, J. S. (1961). Ann. rheum. Dis., 20, 235 Hilder, F. M., and Gunz, F. W. (1964). f. clin. Path., 17, 292.

Olbrich, O. (1948). Edinb. med. 7., 55, 100.

Rentourn, E T (1952) Hum Biol, 24,57.

van Zonneveld, R. J. (1961). The Health of the Aged. Livingstone, Edinburgh.

Vignon, M. G. (1958). Lyon méd., 200, 729.
Westergren, A. (1926). Amer. Rev. Tuberc., 14, 94.

Wilhelm, W. F., and Tillisch, J. H. (1951). Med. Clin. N. Amer., 35, 1209 . 